\title{
Exploring Female Undergraduate Education Students' Perceptions of Collaborative Online Project-Based Learning (COPBL)
}

\author{
Essa A. Alibraheim ${ }^{1 *}$, Sabah A. El-Sayed ${ }^{1}$ \\ ${ }^{1}$ Imam Abdulrahman Bin Faisal University, SAUDI ARABIA
}

Received 21 May $2021 \cdot$ Accepted 7 July 2021

\begin{abstract}
This study aims to identify the perceptions of female student teachers enrolled in the Primary Classroom Teacher Program (PCTP) at a university in Saudi Arabia. It will focus on Collaborative Online Project-Based Learning (COPBL), its advantages, challenges facing the implementation of this strategy, and provide suggestions and recommendations to overcome these challenges. A mixed-method research design was used to analyze the data. Questionnaires were used to collect quantitative data from fifty-five students, and nine of them were interviewed to collect qualitative data. The interview sample was intentionally chosen based on the diversity of responses in the questionnaires. The results of this study revealed that there is a consensus between the perceptions of the study sample in the questionnaires and interviews. Participants showed positive perceptions about COPBL. Researchers presented some recommendations and suggestions at the end of this study.
\end{abstract}

Keywords: students' perceptions, primary classroom teacher program, female undergraduate education students, collaborative online project-based learning, Saudi Arabia

\section{INTRODUCTION}

Teachers play a very important role in raising generations in all societies. Colleges of education are working hard to raise each teacher's capabilities and skills so that they will be able to perform in this profession with a high level of efficiency. Teacher training has become the most effective and successful method for advancing teaching skills and activating their ability to succeed within educational institutions.

Conferences and workshops were held in different countries for the professional preparation of teachers, such as The Sultan Qaboos University International Conference (2004), which emphasized the need develop the programs of College of Education, and to coordinate between teacher preparation institutions and the ministries responsible for education, (Metwally, 2004).

In this context, Furner and Robison (2004) formulated a set of recommendations to develop the teacher preparation program taking into consideration the results of TIMSS (2003). Among these recommendations is the necessity for teacher preparation programs to focus on academic preparation, specifically to focus on the content that the teacher needs after graduation, presenting the content in an in-depth and meaningful manner using physical materials and appropriate technology, and focusing on solving problems in access to new knowledge.

Therefore, new responsibilities have been placed on the teachers, not only in their field of specialization and teaching methods, but also in the extent of their understanding, development of awareness, and reorganization of the requirements of employing this technology. Furthermore, the role of the learner has also increased as well as his dependence on technology, and its use in learning. (Al-Najjar, 2015).

Looking at the strategy of the Collaborative Online Project-Based Learning system (COPBL), it is clear that it focuses on several key components: 1) Electronic sources are used in the implementation of the project. 2) The electronic sources are presented to students using a strategy that shows competition for finding information. 3) It links the information presented to the educational objectives of the e-learning project. 4) The sequence of information implements the project elements, 5) It trains students to take responsibility for the information that

(c) 2021 by the authors; licensee Modestum. This article is an open access article distributed under the terms and conditions of the Creative Commons Attribution License (http://creativecommons.org/licenses/by/4.0/). 


\section{Contribution to the literature}

- The results show that female student teachers had positive perceptions about the Collaborative Online Project-Based Learning (COPBL).

- The study identifies a number of positive aspects to the COPBL strategy, such as it increases positive interaction between students, increases a students' ability to plan the lesson and build electronic activities, and helps build electronic classroom activities in mathematics.

- The findings determine some of the challenges that may face students when applying this strategy, such as including the lack of free software, poor network quality, the lack of equipped laboratories, the need for a great effort from the learners, and the high financial cost compared to traditional learning.

they arrived at and applied in the project. 6) Lastly, it helps students to develop their professional capabilities and link the information they reach and its integration with their colleagues. In doing so, COPBL gives the learners an opportunity for self-realization (Chanpet, Chomsuwan, \& Murphy, 2020; Tolba, 2009).

Many studies (e.g., Chanpet, Chomsuwan, \& Murphy, 2020; Helwa \& Helwa, 2018; Shih \& Tsai, 2017) indicate that COPBL is one of the most effective modern learning strategies. This is especially the case in university education, and it is clearly necessary to train female undergraduate Education students to practice this strategy. Furthermore, according to an overview of current research, the studies conducted on COPBL did not specify the perceptions of female Education students who were enrolled in the Primary Classroom Teacher Program (PCTP) and took the Mathematics Teaching Methods course (MTM). For that, it is hoped that this study will offer a tangible addition to studies in this field.

\section{Research Problem and Questions}

The research problem emerged through two researchers' teaching MTM, which made it difficult for students to understand the course material due to the large amount of theoretical knowledge presented without the appropriate digital applications. Therefore, this research attempts to overcome the difficulty of teaching MTM in the PCTP by employing the COPBL strategy in teaching some of the course topics. This method can provide electronic activities and experiences that students benefit from when studying the theoretical course.

The two researchers conducted personal interviews with some supervisors of practical education in the PCTP, where the supervisors explained the weaknesses of the female undergraduate Education students in the skills of implementing and evaluating mathematics lessons using modern technological applications despite their strong ability to prepare lesson plans. Most of the supervisors attributed the to not benefiting from the application of modern technological methods in preparing these students, training them, and developing their teaching skills.
In addition, Imam Abdulrahman Bin Faisal University provides the Blackboard program for the management of digital education, believing in its importance in teaching university courses. Blackboard contributes to teacher support, the achievement of learning goals and outcomes, and increases the opportunities for participation by students and faculty members.

From this point, the main focus of this research was considering the COPBL strategy and to determine the perceptions of female students who specialize in the PCTP on group projects via the Internet. Thus, the following research questions were formulated:

1. What are the perceptions of the female undergraduate Education students specializing in the PCTP about the COPBL strategy?

2. What are the most important advantages of COPBL from the point of view of the female undergraduate students specializing in the PCTP?

3. What are the most important challenges facing the application of the COPBL strategy from the point of view of the female undergraduate Education students specializing in PCTP?

\section{Research Importance}

The importance of the current study is to enrich the educational literature concerning COPBL and is an attempt to contribute to using COPBL in teaching mathematics courses in the PCTP. program. In addition, the current study will provide those people who are involved in teacher preparation and training with proven effective teaching strategies and methods, such as: COPBL. Also, the study will encourage schools and universities to pay attention to apply this strategy in the classroom.

\section{THEORETICAL FRAMEWORK}

\section{Project-Based Learning}

Project-based learning (PBL) is an instructive strategy operated to involve learners to acquire competences and gain information. Founded on Dewey's notion of learning by doing, the PBL is an efficient teaching strategy that has been used to foster discussion, debate 
(Alozie, Moje, \& Krajcik, 2010) and understanding. (Duncan \& Tseng, 2011). In addition, this strategy completely stimulates learners' attitudes, accomplishment, and forms to track careers (Kanter \& Konstantopoulos, 2010). Jones, Ramussen and Moffitt (1997) defined PBL as an efficient instructional technique that involves learners in acquiring information, skills, and proficiencies through an unlimited inquiry activity arranged around true questions, clearly intended tasks, and products. The PBL is a structure or instructional technique that trains the learners for real life through an increase of personal and learning skills. PBL is defined as collaborative learning in attaining final purposes (Grant, 2011; Hernández-Ramos \& De La Paz, 2009). PBL is thought of as a learning strategy, which is founded on constructivist theory. The major purpose of constructive learning is to improve learner effectual contributions and to reinforce learner motivation and self-directed learning. PBL allows the learner to attain a more profound comprehension of concepts built on the actions involved. In research, Chen and Yang (2019) discovered that PBL had between a median to a greater optimistic effect on the attainments of learners when contrasted with conventional instruction strategies. PBL has also been promoted as an effective and highly regarded way to improve learning (Koh, Herring \& Hew, 2010; Lou \& MacGregor, 2004). From these results, it can be seen that PBL truly increases positive emotions, and skill in learning.

\section{Collaborative Online Project-Based Learning (COPBL)}

COPBL is a unique learner-centered learning strategy. This strategy develops the intrinsic motivation of the learners by allowing them to gain experience in gathering information, categorizing it, and working collaboratively with colleagues. Also, it helps students attain critical thinking skills because it aims to solve realistic problems. Online learners can work in small groups to exchange information and opinions and enable them to communicate with experts of similar interests. Learners have a responsibility to find and formulate the information (Kurubacak, 2007).

Classes that apply COPBL techniques are not without challenges because these classes not only help learners gain new knowledge, but also help them receive meaningful learning experiences. These classes begin by providing real-world problems with which students can ask questions, search for information, brainstorm, come up with alternative solutions, and test those solutions (Yu-Hui \& Yu-Chang, 2013). This strategy helps create a contemplative individual. COPBL helps the learner become independent and find solutions to problems on the ground through learning planning, questioning, systematic and continuous research, and the implementation of many learning methods (ChienLiang, 2018).
Thomas and MacGregor (2005) define COPBL as a learning approach that provides an opportunity for both the teachers and their students to collaborate with each other, through real project-based activities. These activities are not set up using the traditional methods current in schools and universities. COPBL leads to effective learning that encourages more communication and integration between effective learning processes, such as: cooperation, responsibility, participation, and interaction. It also helps interaction between learning outcomes and objectives, such as problem-solving and critical thinking, which leads to the development of skills and knowledge that will be acquired through the Internet.

Zheng and Wang (2008) pointed out that COPBL is an innovative model of education based on a concept of exploration to solve different problems and develop students' motivation towards learning. Also, this educational approach helps students communicate with the real world by undertaking projects that are similar to those they encounter on the ground.

Shadiev, Hwang, and Huang (2015) explained that COPBL is an exemplary educational process for practicing social negotiation skills among students when conducting and implementing an educational project plan by utilizing communication tools in both synchronous and non-synchronous forms, such as email and discussion forums.

Based on the above, the two researchers define the COPBL strategy as an integrated educational learning process in which students participate in undertaking projects and activities to achieve a specific goal. These processes depend on positive participation and cooperative work between female students in the educational system. These projects are done in an environment rich in varied, realistic, digital, and interactive teaching and learning resources, as electronic tools are made use of in their synchronous and nonsynchronous forms. This educational environment is centered around female students, and supports the teacher's role as a facilitator of learning, not as a provider of knowledge.

Ning (2010) identified the characteristics of COPBL, which were:

(1) Learner-centered environment: COPBL integrates content with curriculum standards and foundations, so that there is a clear goal that includes authentic tasks.

(2) Collaboration: learners can acquire the skills of participatory learning.

(3) Multiple presentation modes: learners can use various forms of technology effectively.

(4) Time Management: students in COPBL can determine the time they will spend on the learning process and in undertaking the project. 


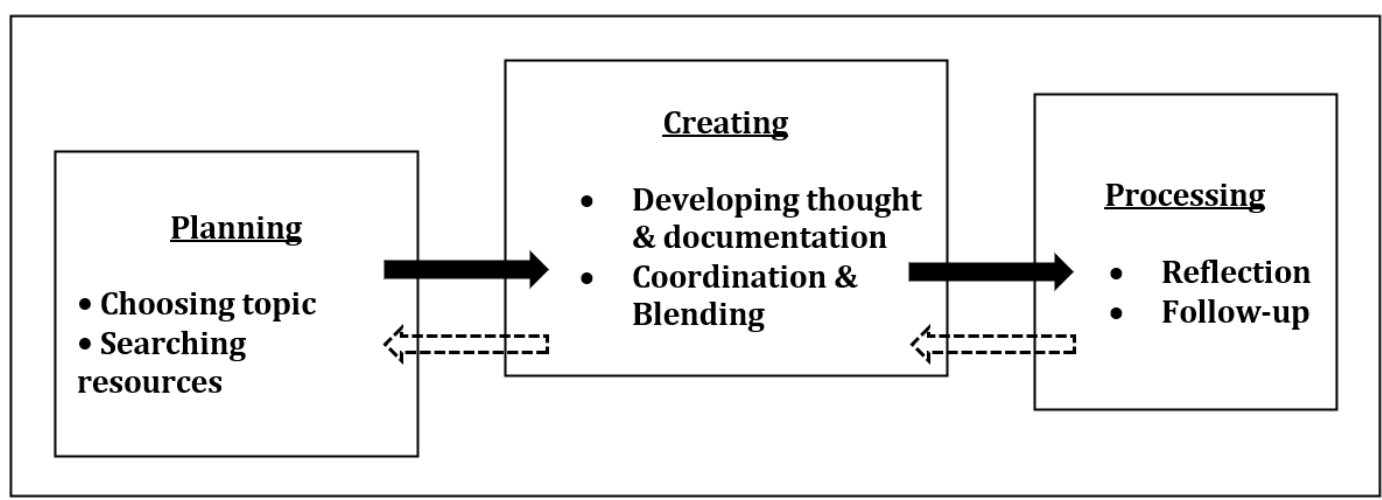

Figure 1. General framework for the COPBL (Ning, 2010, p. 172)

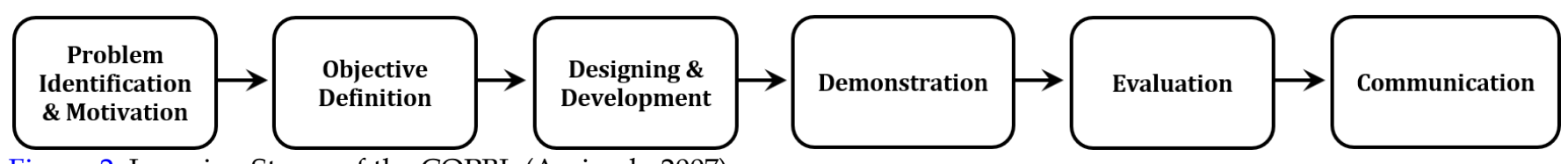

Figure 2. Learning Stages of the COPBL (Amissah, 2007)

(5) Innovative Assessment: COPBL requires an innovative evaluation where the learners evaluate themselves, and their colleagues, so that the evaluation is not limited to the teacher only, as was previously the case.

Koh, Herring, and Hew (2010) suggested four guiding phases for implementing COPBL to promote knowledge building in students, which were:

(1) Identifying the problem for students: The problem must be appropriately complex to ensure that feedback is provided, and that students learn well.

(2) Structuring project milestones to facilitate knowledge building: Project structuring helps students advance from exploring an idea to presenting solutions to a problem.

(3) Encouraging students to express their learning through developing project models: Producing student models helps to improve the building process of their knowledge and can also be used to stimulate the social construction of knowledge when accompanied by feedback and criticism from the teacher and peers.

(4) Evaluate students' knowledge building, and use appropriate moves to advance students to higher levels of current knowledge.

COPBL can develop students' ability to solve problems through communication with others, reflective thinking, cooperative learning, and the production of a collective product. COPBL is increasingly used as a teaching and learning method in university education to promote knowledge building through social interaction (Lin \& Tsai, 2016).

Ning (2010) identified three phases of COPBL's implementation, which are: planning, creation or implementation (creativity), and processing, as shown in the Figure 1.
Amissah (2019) provided an applied example of the COPBL's procedures through the stages shown in Figure 2.

Mobarez (2014) referred to COPBL's strategy as one of the strategies that rely on performance-based evaluation. This strategy depends on the students' implementation of projects to evaluate their performance and learning on the subject. Therefore, the final project product is evaluated. Students also conduct many tasks, activities and processes during project completion. Then, evaluation mechanisms are identified that are compatible with project learning, whether evaluating the project completion processes or the final project product.

Several studies have focused on COPBL's strategy and its implementation in the educational process to achieve many learning outcomes, including: Marhoon's study (2012), which showed several results, such as the effectiveness of project-based digital training in developing digital content design skills for primary school teachers. However, there is no effectiveness of project-based digital training in developing attitudes towards training for primary school teachers. Ahmed's study (2015) showed the effectiveness of the modeling method by participating in the online project environment on developing the performance aspect of the e-course design skills.

Elrefaie's study (2015) found improvement in both attitudes towards project work and performance in students who studied using integrated project learning with Web 2.0 network technology and compared this with students who did not learn using that approach. Shih and Tsai (2017); and Chanpet, Chomsuwan, and Murphy (2020) both agree that the COPBL strategy enhances students' learning, motivation, and interest in learning. Also, this strategy enhances student teamwork and increases their interaction with their teachers. 
Whereas, the study of Muhammad (2018) found the effectiveness of a proposed program in procedural research using COPBL improved research awareness and reduced teaching anxiety for female student teachers, majoring in mathematics at Majmaah University in Saudi Arabia.

Helwa and Helwa (2018) found that COPBL requires students to participate positively and actively in learning. A teacher becomes a mentor after being an expert in educational content. Students' language learning improves by utilizing technology to access and analyze information from various fields in the world. Lin (2018) developed a tool to measure university students' project efficiency in the COPBL environment. Three dimensions of the tool have been developed, namely: knowledge integration, project skills, and self-efficacy. In addition, Almuwallad (2019) demonstrated the effectiveness of COPBL in developing achievement and self-organization skills in physics for high school students.

Based on the previous review of studies related to electronic projects, most of the studies conducted on electronic projects agreed on their effectiveness in developing and improving a number of variables among students such as: academic achievement, attitudes towards learning by electronic projects, self-organizing skills, self-organized learning, foreign language learning, research awareness and reduced teaching anxiety, course design skills, digital content, digital interaction and participation. While the study of Taher (2017) confirmed that peer support when implementing electronic projects has an effective impact on students' performance compared to teacher support in the case of applying the same strategy. Peer support helps students to be positive, interact, and actively participate in the project.

\section{Perceptions of Female Undergraduate Education Students}

Several researchers have indicated that there are strong links between teachers' perceptions and classroom behaviors. These perceptions act as guides for their behaviors and practices. Knowing the perceptions of the student teachers helps to predict achievement, and the extent of the student's success or failure in the teaching profession. The ability to choose the activities and topics they can practice can also be determined by student perceptions. Studies have confirmed that the COPBL strategy gives students a positive attitude towards teaching. The study of Elrefaie (2015), Aref (2015), and Al-Daba (2014) showed the effect of electronic projects on achieving effective and positive attitudes. Meanwhile, Marhoon (2012) differed in that, it showed that there was no effect of e-training in the projects strategy on the attitude towards the training of teachers in primary schools. On the other hand, Shih and Tsai (2017), and Chanpet, Chomsuwan, and Murphy
(2020) found that learners have positive perceptions of the e-project learning environment and that their knowledge and skills were much higher than those in the normal project learning environment. Baser, Ozden, and Karaarslan (2017) concluded that COPBL had an effect on improving students' perceptions, developing their collaborative and technical skills, as well as providing an exemplary collaborative learning experience. A study by Zhang, Peng, and Hung (2009) indicated that students, through their observations and interviews in COPBL, gained a tremendous amount of knowledge, learned computer skills, and confirmed the positive outcomes of the learning experience from electronic projects, despite their concerns about a radical shift in their profession and the roles of a teacher in the future.

\section{METHODOLOGY}

In the current research, a mixed methods design was used with its quantitative and qualitative methods. The questionnaire was used to determine the perceptions of female undergraduate Education students enrolled in the PCTP about COPBL at Imam Abdulrahman Bin Faisal University (IAU). Personal interviews were used to determine the most important positives and challenges facing the implementation of the COPBL strategy from the viewpoint of the female undergraduate Education students, specializing in PCTP.

\section{Research Population}

All female Education students specializing in the PCTP were enrolled in the seventh semester of the MTM course at the College of Education, Imam Abdulrahman Bin Faisal University, in the academic year 2019/2020.

\section{Research Sample}

The study sample includes the following:

1. A representative sample of the study population was purposefully selected consisting of 55 female undergraduate Education students enrolled in the MTM course in the seventh semester at the College of Education, IAU, in the academic year 2019/2020, where the COPBL strategy was applied to them, and then the questionnaire collected.

2. The interviews were conducted with a sample of 9 female undergraduate Education students from the participants in the questionnaire. All interviews were conducted in the academic year 2019/2020.

\section{Instrumentation}

The current research used the following research instrumentation:

1. The questionnaire contains elements in a fivepoint Likert format (Strongly Agree, Agree, Not sure, Disagree, Strongly Disagree). The questionnaire was 
Table 1. Cronbach's alpha coefficients

\begin{tabular}{lcc}
\hline The Dimension of the Scale & Items Number & Cronbach's Alpha \\
\hline Cognitive presence & 8 & 0.77 \\
social presence & 7 & 0.76 \\
Motivation Learning & 7 & 0.81 \\
The total score of the scale & 22 & 0.82 \\
\hline
\end{tabular}

applied to a sample of (55) female undergraduate Education students, in order to get acquainted with their perceptions of the COPBL strategy. The questionnaire was presented in its initial form to a number of referees from the faculty who are specialized in the field of curricula and instruction, in order to allow them to express their observations and suggestions in terms of: the suitability of the tool to achieve the goal for which it was set, the validity of the content, the adequacy of the content, the integrity and accuracy of the phrases, and their clarity. Adjustments were made in the light of the opinions of the referees to reach a final version of the questionnaire. Therefore, the validity of the instrument was verified by what is known as construct validity. The reliability of the questionnaire was also calculated by applying it to a sample of female undergraduate Education students, where the value of the Cronbach's alpha coefficient was 0.83 , which is an acceptable value for reliability. and the results are as demonstrated in Table 1.

2. An interview form was applied to (9) female undergraduate Education students after being presented to a number of specialized faculty members for arbitration and was approved. The first interview question was a set of preliminary questions to identify the students' data. The second question was an openended question about the MTM course and teaching methods. The third part was a question focusing on the participants' knowledge of COPBL, and the difference between COPBL and traditional projects. Finally, questions were asked that identified the role of students and the teachers while using COPBL, the most important advantages of COPBL strategy, and the most important challenges facing the application of learning within that strategy.

These interview questions were presented to a number of referees specialized in Curricula and Instruction. Adjustments to the wording were made according to referee views. Interview questions were tested with five female undergraduate Education students, specializing in the PCTP other than the participants in this study, to ensure the clarity of the questions and estimate the time required to complete the interviews. All the five students took approximately (20) minutes to finish the interview.

\section{Research Delimitations}

The delimitations of this research were:
1. A sample of female undergraduate Education students specializing in the PCTP at IAU.

2. The COPBL strategy was applied in the subjects of the MTM course for the first semester of the academic year 2019/2020.

\section{Research Terms}

\section{Collaborative Online Project-Based Learning (COPBL)}

It was defined in this research as: a system of procedures that depend on group work among female students specializing in the PCTP based on specific procedural stages that begin with an introduction to the project, developing a time plan for each group of students, and the appropriate design was made through discussions. Then, these designs are presented through the group forum and published in the public forum of the MTM course.

\section{Female undergraduate Education students specializing in the Primary Classroom Teacher Program (PCTP)}

They are female students who are enrolled in the College of Education at Imam Abdulrahman bin Faisal University, in the Curriculum and Instruction Department. They are specializing in PCTP (they will teach grade 1 to 3 in elementary school after they graduate). These students were in semester seven, and registered in the MTM course.

\section{Female undergraduate Education students' Perceptions about the strategy of COPBL}

It is defined in this research as: the viewpoint of female undergraduate Education students who specialize in PCTP or their perceptions of the effectiveness of using COPBL in the MTM course, which they express by answering the questionnaire in this study.

\section{Statistical Analysis}

The questionnaire data were processed using the SPSS program, which calculated the score of the means and standard deviations of the responses of the sample. A qualitative analysis of the results of the personal interviews were also performed. 


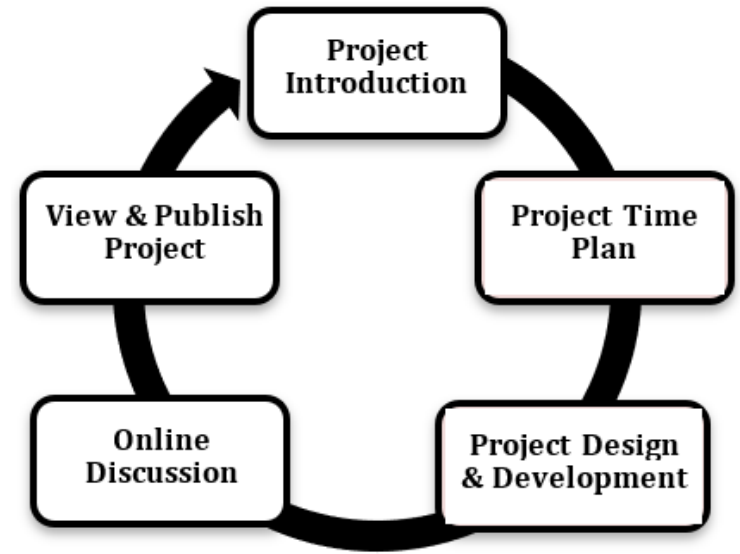

Figure 3. The general framework for the COPBL steps as determined by the researchers

\section{Teaching Procedures in the COPBL Strategy}

Based on the researchers' review of previous literature, a framework was developed that includes the COPBL's stages, as following:

1. Identifying the introduction of the project: After the teacher presents the lesson in the class, an introduction to the lesson project is presented, which aims to push the students to learn by asking them a question or presenting a task.

2. Determine the time plan for the project: the project goal is formulated, and a time plan is drawn up for implementation, with the students divided into cooperative groups.

3. Project Design and Development: Female students in each group begin designing their project.

4. Using forums to discussions: Students in each group confer with each other to solve the obstacles and difficulties they face online. The teachers' role at this stage is to guide, and this step is done asynchronously.

5. Presentation and dissemination of projects online: The aim of this step is peer and teacher review, and exchange of views between groups.

The syllabus of the MTM course in the PCTP, which was taught at IAU, has been adhered to. The course was taught for the research sample for a period of 6 weeks, during the 2019/2020 academic year.

The course includes six projects as follows:

1. Creating interactive activities in mathematics in smart notebook software.

2. Creating an electronic story in mathematics using Animaker software.

3. Creating an educational Mathematics platform through Google Classroom.

4. Preparing an electronic game in mathematics using the tinytap app.
5. Preparing a presentation for one of the mathematics lessons using PowerPoint.

6. Creating an electronic portfolio in the sway program.

Topics of the MTM have been reformulated so that each topic includes a project for online project-based learning groups. The recorded lectures were uploaded a week ahead of time through Blackboard. The registered students in the course can access the course page through their usernames and passwords. The course page allows students to download video lectures or worksheets. Also, communication between the teachers and their students through the forums and the university e-mail was enacted. Students received notifications of the course projects, or any other instructions, through the course page. The course forum was used for discussion between students about their projects. Students sent assignments as attachments. Projects and feedback were evaluated and then resent again after modifying the notes.

\section{RESULTS \& DISCUSSION}

The questionnaire was distributed to all female undergraduate Education students, specializing in PCTP, who are enrolled in the MTM course in the seventh semester at the College of Education, IAU, after teaching them with the COPBL strategy. The number of participants were 55 female students. Data were collected in the academic year 2019/2020, and then were analyzed statistically using SPSS.

To answer the first research question, which stated, "What are the perceptions of the female undergraduate Education students specializing in the PCTP about the COPBL strategy" The scores of means and standard deviations were calculated to clarify the perceptions of the participants towards COPBL. Table 1 provides the scores and order of the three domains of the sample's perceptions about the strategy. The level of students' perceptions was considered low when the mean score was between $(1-2.33)$, medium level between $(2.34$ $3.67)$, and a high level between (3.68 - 5), as shown in Table 2.

From Table 1, the total students' perceptions about the importance of the COPBL strategy in developing the cognitive presence of female undergraduate Education students specializing in the PCTP was high, where the mean score was $(M=4.16)$. All the statements for this domain were high, as the mean scores ranged between (4.71 - 3.18). Statements number (2), which is "The COPBL strategy contributes to increasing the uptake of the educational material", had the highest score $(M=4.71, S D$ $=0.57)$. While statements number (1), which is "The Collaborative Online Project-Based Learning (COPBL) strategy shapes the creative minds of students", got the lowest score $(M=3.18, S D=0.61)$. 
Table 2. The descriptive statistics of questionnaire

\begin{tabular}{|c|c|c|c|c|c|c|}
\hline & & Statement & Mean & SD & Level & Order \\
\hline \multirow{8}{*}{ 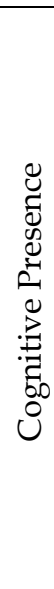 } & 1 & $\begin{array}{l}\text { The Collaborative Online Project-Based Learning (COPBL) strategy } \\
\text { shapes the creative minds of students. }\end{array}$ & 3.18 & .61 & Medium & 8 \\
\hline & 2 & $\begin{array}{l}\text { The COPBL strategy contributes to increasing the uptake of the } \\
\text { educational material. }\end{array}$ & 4.71 & .57 & High & 1 \\
\hline & 3 & The COPBL's strategy helps develop higher-order thinking skills. & 4.60 & .49 & High & 2 \\
\hline & 4 & $\begin{array}{l}\text { The COPBL's strategy takes into account individual differences among } \\
\text { students. }\end{array}$ & 3.93 & .26 & High & 6 \\
\hline & 5 & $\begin{array}{l}\text { The COPBL's strategy encourages an exchange of experiences between me } \\
\text { and my colleagues. }\end{array}$ & 3.80 & .40 & High & 7 \\
\hline & 6 & $\begin{array}{l}\text { The COPBL's strategy makes it easier for students to complete homework } \\
\text { and course assignments. }\end{array}$ & 4.55 & .66 & High & 3 \\
\hline & 7 & $\begin{array}{l}\text { I believe that the COPBL's strategy helps in developing the problem- } \\
\text { solving skills of female students. }\end{array}$ & 4.53 & .66 & High & 4 \\
\hline & 8 & I see that the COPBL's strategy develops self-learning skills. & 4.00 & .61 & High & 5 \\
\hline \multicolumn{2}{|c|}{ Sub-total } & & 4.16 & .23 & High & \\
\hline \multirow{7}{*}{ 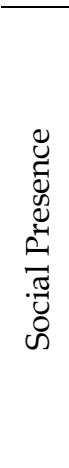 } & 9 & The COPBL's strategy increases interaction between students. & 4.47 & .50 & High & 2 \\
\hline & 10 & $\begin{array}{l}\text { The COPBL's strategy increases the positive interaction between me and } \\
\text { the course teacher. }\end{array}$ & 4.36 & .80 & High & 3 \\
\hline & 11 & $\begin{array}{l}\text { The COPBL's strategy increases the opportunities for discussion among } \\
\text { students about how to design projects. }\end{array}$ & 3.55 & .69 & Medium & 5 \\
\hline & 12 & $\begin{array}{l}\text { The COPBL's strategy makes a student able to handle new situations with } \\
\text { confidence and without hesitation. }\end{array}$ & 3.49 & .57 & Medium & 6 \\
\hline & 13 & The COPBL's strategy helps me to accept the views of others. & 4.62 & .78 & High & 1 \\
\hline & 14 & $\begin{array}{l}\text { The COPBL's strategy facilitates scientific communication between } \\
\text { students. }\end{array}$ & 3.80 & .68 & High & 4 \\
\hline & 15 & The COPBL's strategy abolishes the human aspect in learning. & 2.07 & .66 & Low & 7 \\
\hline \multicolumn{2}{|c|}{ Sub-total } & & 3.77 & .29 & High & \\
\hline \multirow{7}{*}{ 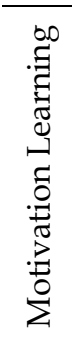 } & 16 & The COPBL's strategy helps take responsibility for learning. & 4.49 & .50 & High & 4 \\
\hline & 17 & The COPBL's strategy helps to enjoy studying the course. & 4.62 & .49 & High & 2 \\
\hline & 18 & The COPBL's strategy gets me bored when someone talks to me about it. & 2.42 & .50 & Low & 7 \\
\hline & 19 & I feel the COPBL's strategy meets students' needs. & 4.42 & .49 & High & 5 \\
\hline & 20 & $\begin{array}{l}\text { I see the COPBL's strategy increases my confidence in learning the } \\
\text { contents of the course. }\end{array}$ & 4.35 & .95 & High & 6 \\
\hline & 21 & I see the COPBL's strategy increases students' eagerness for learning. & 4.58 & .49 & High & 3 \\
\hline & 22 & I love being a teacher who uses the COPBL's strategy in the classroom. & 4.67 & .47 & High & 1 \\
\hline \multicolumn{2}{|c|}{ Sub-total } & & 4.22 & .19 & High & \\
\hline \multicolumn{2}{|c|}{ Total } & & 4.05 & .142 & High & \\
\hline
\end{tabular}

These results confirm what Helwa and Helwa (2018) indicated showing COPBL is one of the teaching strategies in which the student has a major role. Also, this strategy helps to develop thinking skills. In addition, COPBL develops the skills of the left side of the brain, which are represented in remembering, understanding and analysis, as well as the skills of the right side of the brain, which are represented in synthesis and Inventive Creativity. Omale et al. (2009) also indicated the importance of online project-based learning environment on increasing students' academic understanding and achievement.

It is also shown from Table 1 that the total students' perceptions about the COPBL strategy in developing social presence among female undergraduate Education students specializing in the PCTP was high, where the mean score was $(M=3.77)$. All the statements for this domain also were high, as the mean scores ranged between (4.62 - 2.07). Statement number (13), which is "The COPBL's strategy helps me to accept the views of others", had the highest score $(M=4.62, S D=0.78)$. While statement number (15), which is "The COPBL's strategy abolishes the human aspect in learning", got the lowest score $(M=2.07$, $S D=0.66)$.

The above findings are consistent with what has been indicated by many previous studies such as (e. g., Heo, Lim, \& Kim, 2010; Gwen, 2003; Sendag \& Odabasi, 2009) that have implemented online project-based learning. They illustrated that this strategy increases the effectiveness of learning. The use of hyperlinks, hypertexts, hypermedia, and databases helps enrich the student's learning environment. Dealing with forums, email, and chat rooms also helps increase social interaction, and provides students with greater opportunities to interact with peers while working on the project. 
Table 3. Level and order of the perceptions of the female undergraduate education students according to the questionnaire's domains

\begin{tabular}{lcccc} 
Domain & Mean & SD & Perceptions Level & Perceptions Order \\
\hline Motivation learn & 4.22 & .19 & High & 1 \\
Cognitive presence & 4.16 & .23 & High & 2 \\
Social presence & 3.77 & .29 & High & 3 \\
\hline Total & 4.05 & .142 & High & \\
\hline
\end{tabular}

Finally, Table 1 provides the total students' perceptions about the importance of the COPBL strategy in developing motivation learning among female undergraduate Education students specializing in the PCTP. This was high, where the mean score was $(M=$ 4.22). All the statements for this domain were also high, as the mean scores ranged between (4.67 - 2.42). Statement number (22), which is "I love being a teacher who uses the COPBL strategy in the classroom", had the highest score $(M=4.67, S D=0.47)$. While statement number (18), which is "The COPBL's strategy gets me bored when someone talks to me about it", got the lowest score $(M=$ 2.42, $S D=0.50)$.

These results indicate that COPBL not only helps in developing students' ability to solve problems and cognitive learning, but also makes learners more involved in the learning process. Additionally, COPBL's outputs include the development of students' sense of achievement and pride, as well as increased self-growth (for example, confidence, self-esteem, and responsibility), increased participation in learning, and students' acquisition of empathy for others. Every student is allowed to form an opinion and every student can feel positive about their contribution. Interest and motivation to participate in the project also increases, and these contribute to students' success in learning (Carr \& Jitendra, 2000; Matejka, 2004).

The mean score and standard deviations were used to clarify the level and order of the students' perceptions in the three domains of the questionnaire. Table 2 shows the level and order of the domains of perceptions about the COPBL from the point of view of pre-service female teacher, specializing in the PCTP.

Table 2 emphasizes that the perceptions of female undergraduate Education students about the COPBL strategy were high. The mean score of the study sample on the questionnaire statements was $(M=4.05)$, and this value is high. This finding is due to the fact that the COPBL strategy works to develop cognitive and social skills, and motivates students to learn. This was done because students have a greater opportunity to pose ideas, questions, and come to conclusions and expectations. In addition, students gain the benefit of working in groups of intellectual richness and discussions, exchanging ideas and opinions, designing and presenting projects to the rest of the students. In this system, the teacher's role becomes one of a mentor, and provides encouragement. This result is consistent with the results of the study of Al-Dabba (2014), Aref (2015),
Baser, Ozden, and Karaarslan (2017), Chanpet, Chomsuwan, and Murphy (2020), Elrefaie (2015), Shih and Tsai (2017), and Zhang, Peng, and Hung (2009).

To answer the second question, which was "What are the most important advantages of COPBL from the point of view of female undergraduate Education students specializing in the PCTP?" The results of the quantitative analysis agreed with the results of the qualitative analysis, where the results of the interviews showed that four participants $(44 \%)$ believed that there were many important advantages of COPBL. Some of these were increasing students' motivation towards learning, developing the ability to understand, retaining learning for a longer period, helping to develop self-learning skills, contributing in developing the skills of online research, increasing interaction between colleagues during the implementation and design of projects, obtaining appropriate feedback from the course teacher, contributing to increasing the student's ability to plan mathematics lessons, producing digital teaching aids and evaluation, helping to build classroom activities in mathematics by selecting the best sources of learning and technology, and finally helping to link the teaching of mathematics to other courses.

The reason for this result is that the COPBL strategy is effective as it includes new scientific, artistic, and technical directions. This strategy combines the advantages of both traditional and e-learning. As we all know, the Internet has become the language of the age, which helps students to access the knowledge they need during the learning process. Thus, students feel pleasure while dealing with educational technologies within the educational website of the university, and communication and interaction through a number of media such as: university e-mail, intellectual forums, written interaction and others. In addition, the face-toface education in the lectures helps students to interact with each other and members of the faculty. Moreover, feedback and social interaction are also a significant aspect of COPBL. The results of the second question agreed with the study of Al-Daba (2014), Aref (2015), Chanpet, Chomsuwan, and Murphy (2020), Elrefaie (2015), and Shih and Tsai (2017).

To answer the third question, which stated, "What are the most important challenges facing the application of the $C O P B L$ strategy from the point of view of female undergraduate Education students specializing in the PCTP?" The results of the interviewees showed that six of the participants $(67 \%)$ confirmed that the most 
important challenges facing the COPBL are the lack of free software that can be used in learning, poor Internet connections, the lack of smart boards in the classroom, the lack of availability laboratories that help them to use the COPBL strategy, and the lack of specialized websites that can be used in building activities for the MTM course. In addition, students' poor computer skills, the work of appropriate educational software for the course, the need for a great effort from the learners in preparing and designing, the difficulty of evaluating the performance of students after the implementation of the strategy, and finally the lack of financial support for its implementation by the students, as the activities of this strategy are costly compared to traditional learning.

The result of this question is consistent with what some researchers (Dridi et al., 2020; Goode et al., 2018; Kaur, 2013; Woodall, 2010) have indicated about the challenges facing the application of blended learning in general, and the COPBL's strategy in particular. These challenges are the difficulty of accessing the Internet, reorganizing the classroom environment in proportion to blended learning, meeting all students at the same time online, the need for workplaces and high-speed networks, the need for the teacher to possess the technical skills necessary for this type of learning, and providing all the necessary materials for the sessions to be interactive so that the learner does not lose interest and become passive.

From the previous discussions, a number of proposals and recommendations can be reached. (1) Activating the e-projects strategy within the university curricula can be accomplished by updating the academic curricula, and developing application programs to employ them in all courses. (2) Working on launching interactive digital platforms as well as launching educational satellite channels to help students who do not have access to the Internet. (3) Holding training courses for in-service teachers in elementary schools to clarify the e-projects strategy, and its benefits in improving students' academic achievement. (4) Employing all kinds of educational technologies in spreading academic courses, communicating between students, searching for knowledge, and providing an opportunity for self-learning to facilitate student learning.

The current study also proposes conducting another similar study that focuses more on training in-service female teachers in elementary school to employ the eproject strategy, and measure its impact on their teaching performance. In addition, further studies are proposed to verify the reliability and effectiveness of the COPBL's strategy.

\section{CONCLUSION}

This study aimed to reveal the perceptions of female undergraduate Education students who specialize in the
Primary Classroom Teacher Program (PCTP) based on Collaborative Online Project-Based Learning (COPBL). In addition, this paper strived to identify the most important advantages and challenges facing the application of this strategy from the viewpoint of female undergraduate Education students using a mixedmethod research design. The quantitative data showed that the participants' perceptions were positive in the three domains of the questionnaire (cognitive presence social presence - motivation learn). The results of the qualitative data supported the results of the quantitative analysis, as the results of the qualitative analysis showed a number of positive aspects to the COPBL strategy, which are that it increases positive interaction between students, facilitates understanding of the course, increases a students' ability to plan the lesson and build electronic activities, helps in producing digital teaching aids and evaluation, and helps build electronic classroom activities in mathematics. On the other hand, participants expressed some of the challenges that they faced when applying this strategy in the Mathematics Teaching Methods (MTM) course, including the lack of free software, poor network quality, the unavailability of smart boards in the classrooms, the lack of equipped laboratories, the lack of specialized sites that can be used in building course activities, the students' poor skills in computers and in educational software, the need for a great effort from the learners, and the high financial cost compared to traditional learning. Although the number of female interviewees was limited $(n=9)$, the available time for the personal interview allowed researchers to obtain deep qualitative data on the main advantages and challenges facing the application of this strategy in the MTM course. The two researchers suggest conducting similar research in other academic stages, and testing the extent of COPBL's effectiveness on students' perceptions and attitudes in various fields.

Author contributions: All authors have sufficiently contributed to the study, and agreed with the results and conclusions.

Funding: No funding source is reported for this study.

Declaration of interest: No conflict of interest is declared by authors.

\section{REFERENCES}

Ahmed, I. (2015). The impact of using different methods of e-modeling on web projects-based learning on cognitive achievement and development skills of designing e-courses among female students of instructional technology. Egyptian Association for Educational Technology, 25(4), 81-123.

Al-Daba, M. (2014). The effectiveness of the e-projects strategy in developing electronic interaction, sharing, and the attitude toward it among students of the college of education at the islamic university - gaza. [Unpublished Master Thesis]. Islamic University Gaza. 
Almuwallad, N. (2019). The effectiveness of projectbased learning via the web in developing achievement and self-organization skills in physics for high school students. The Arab Journal of Qualitative Education, 8, 37-68.

Al-Najjar, H. (2015). The effectiveness of a training program in developing electronic teaching skills and attitudes towards it among secondary school teachers in Gaza. Al-Manara Journal for Research and Studies, 21(2), 306-344.

Alozie, N. M., Moje, E. B., \& Krajcik, J. S. (2010). An analysis of the supports and constraints for scientific discussion in high school project-based science. Science Education, 94(3), 395-427. https:/ / doi.org/10.1002/sce.20365

Amissah, P. (2019). Advantages and challenges of online project based learning [Thesis]. College of Art and Design of the Rochester Institute of Technology.

Aref, A. (2015). The effectiveness of using two types of the project-web based learning individual and collaborative in developing e-books designing skills among female prospective teachers and their attitude towards the project-web based learning strategy. Journal of Arab studies in education and Psychology, 59, 69-118. https://doi.org/10.12816/ SAEP.2015.60869

Baser, D., Ozden, M. \& Karaarslan, H. (2017). Collaborative project-based learning: An integrative science and technological education project. Research in Science \& Technological Education, 35(2), 131-148. https://doi.org/10.1080/02635143. 2016.1274723

Carr, T., \& Jitendra, A. K. (2000). Using hypermedia and multimedia to promote project-based learning of at-risk high school students. Intervention in School $\mathcal{E}$ Clinic, 36(1), 40-44. https://doi.org/10.1177/ 105345120003600106

Chanpet, P., Chomsuwan, K., \& Murphy, E. (2020). Online project-based learning and formative assessment. Technology, Knowledge and Learning, 25(3), 685-705. https://doi.org/10.1007/s10758018-9363-2

Chen, C. H. \& Yang, Y. C. (2019). Revisiting the effects of project-based learning on students' academic achievement: A meta-analysis investigating moderators. Educational Research Review, 26, 71-81. https:// doi.org/10.1016/j.edurev.2018.11.001

Chien-Liang, L. (2018). The development of an instrument to measure the project competences of college students in online project-based learning. Journal of Science Education and Technology, 27(1), 5769. https:/ / doi.org/10.1007/s10956-017-9708-y

Dridi, M., Radhakrishnan, D., Moser-Mercer, B., \& DeBoer, J. (2020). Challenges of blended learning in refugee camps: When internet connectivity fails, human connection succeeds. International Review of Research in Open and Distributed Learning, 21(3), 250263.

Duncan, R.G., \& Tseng, K. A. (2011). Designing projectbased instruction to foster generative and mechanistic understandings in genetics. Science Education, 95(1), 21-56. https://doi.org/10.1002/ sce. 20407

Elrefaie, A. (2015). The effect of project based instruction approach with web 2.0 on statistics achievement and attitudes towards teamwork projects for students of economics. Journal of Educational and Psychological Sciences, 16(3), 325-360. https:/ / doi.org/10.2307/748616

Furner, J. M., \& Robison, S. (2004). Using TIMSS to improve the undergraduate preparation of mathematics teachers. Issues in the Undergraduate Mathematics Preparation of School Teachers, 4, 1-10.

Goode, C. T., Lamoreaux, M., Atchison, K. J., Jeffress, E. C., Lynch, H. L., \& Sheehan, E. (2018). Quantitative skills, critical thinking, and writing mechanics in blended versus face-to face versions of a research methods and statistics course. Teaching of Psychology, 45(2), 124-131. https:/ / doi.org/10.1177 /0098628318762873

Grant, M. (2011). Learning, beliefs, and products: Students' perspectives with project-based learning. The Interdisciplinary Journal of Problem-Based Learning, 5(2), 37-69. https://doi.org/10.7771/ 1541-5015.1254

Gwen, S. (2003). Project-based learning: A primer. Technology \& Learning, 23(6), 20-27.

Helwa, H., \& Helwa, S. (2018). Online project based instruction in English language learning: Theory and practice. Journal of Research in Curriculum, Instruction $\mathcal{E}$ Educational Technology, 4(1), 155-173. https://doi.org/10.21608/jrciet.2018.24492

Heo, H., Lim, K. Y., \& Kim, Y. (2010). Exploratory study on the patterns of online interaction and knowledge co-construction in project-based learning. Computers $\mathcal{E}$ Education, 55(3), 1383-1392. https://doi.org/10.1016/j.compedu.2010.06.012

Hernández-Ramos, P., \& De La Paz, S. (2009). Learning history in middle school by designing multimedia in a project-based learning experience. Journal of Research on Technology in Education, 42(2), 151-173.

Jones, B. F., Rasmussen, C. M., \& Moffit, M. C. (1997). Psychology in the classroom: A series on applied educational psychology. Real-life problem solving: A collaborative approach to interdisciplinary learning. American Psychological Association. https: / / doi.org/10.1037/10266-000

Kanter, D. E., \& Konstantopoulos, S. (2010). The impact of a project-based science curriculum on minority student achievement, attitudes, and careers: The 
effects of teacher content and pedagogical content knowledge and inquiry-based practices. Science Education, 94(5), 855-887. https:/ / doi.org/10.1002/ sce.20391

Kaur, M. (2013). Blended Learning - Its Challenges and Future. Procedia - Social and Behavioral Sciences, 93, 612-617.

https:// doi.org/10.1016/j.sbspro.2013.09.248

Koh, J. H. L., Herring, S. C., \& Hew, K. F. (2010). Projectbased learning and student knowledge construction during asynchronous online discussion. The Internet and Higher Education, 13(4), 284-291.

https:/ / doi.org/10.1016/j.iheduc.2010.09.003

Kurubacak, G. (2007). Promoting self-motivated learning through project based online learning. I-Manager's Journal of Educational Technology, 3(4), 9-18.

Lin, C. (2018). The development of an instrument to measure the project competences of college students in online project-based learning. Journal of Science Education and Technology, 27(1), 57-69. https://doi.org/10.1007/s10956-017-9708-y

Lin, J. (2018). Effects of an online team project-based learning environment with group awareness and peer evaluation on socially shared regulation of learning and self-regulated learning. Behaviour \& Information Technology, 37(5), 445-461. https:/ / doi.org/10.1080/0144929X.2018.1451558

Lin, J., \& Tsai, C. (2016). The impact of an online projectbased learning environment with group awareness support on students with different self-regulation levels: An extended-period experiment. Computers E Education, 99, 28-38. https://doi.org/10.1016/ j.compedu.2016.04.005

Lou, Y., \& MacGregor, S., K. (2004). Enhancing projectbased learning through on-line between-group collaboration. Educational Research \& Evaluation, 10(4), 419-440. https://doi.org/10.1080/138036105 12331383509

Marhoon, R. (2012). The effect of projects-based e-training on the skills of designing e-content and attitude towards training among primary stage teachers [Unpublished Master Thesis]. Arabian Gulf University.

Matejka, D. (2004). Project-Based Learning in Online Postgraduate Education. Issues in Informing Science $\mathcal{E}$ Information Technology, 1, 489-496. https:/ / doi.org/10.28945/754

Metwally, A. (2004, July 21-22). Developing mathematics teacher training programs in the sultanate of oman in light of contemporary global attitudes. Sixteenth Scientific Conference-Teacher Composition. Ain Shams University, Egypt.

Mobarez, M. (2014). The difference in the type of performance-based assessment in the web-based project learning strategy and its impact on developing problem-solving skills and the power of cognitive control in the computer and information technology course among middle school students. Egyptian Association for Educational Technology, 24(1), 239-279.

Muhammad, R. (2018). Proposed program in action researches based on Project-web learning in developing research awareness and decrease the teaching anxiety for female mathematics prospective teachers. Journal of Mathematics Pedagogy, 21(4), 168-223.

Ning, B. (2010). Applying project-based learning to product design teaching. 2010 International Conference on System Science, Engineering Design and Manufacturing Informatization, System Science, Engineering Design and Manufacturing Informatization (ICSEM), 2010 International Conference On, 1, 171-173. https://doi.org/ 10.1109/ICSEM.2010.52

Omale, N., Hung, W., Luetkehans, L., \& Cooke, P. J. (2009). Learning in 3-D multiuser virtual environments: Exploring the use of unique 3-D attributes for online problem-based learning. British Journal of Educational Technology, 40(3), 480495. https://doi.org/10.1111/j.1467-8535.2009. 00941.x

Sendag, S., \& Odabasi, H. F. (2009). Effects of an online problem-based learning course on content knowledge acquisition and critical thinking skills. Computers $\mathcal{E}$ Education, 53(1), 132-141. https://doi.org/10.1016/j.compedu.2009.01.008

Shadiev, R., Hwang, W., \& Huang, Y. (2015). A pilot study: Facilitating cross-cultural understanding with project-based collaborative learning in an online environment. Australasian Journal of Educational Technology, 31(2), 123-139. https:/ / doi.org/10.14742/ajet.1607

Shih, W., \& Tsai, C. (2017). Students' perception of a flipped classroom approach to facilitating online project-based learning in marketing research courses. Australasian Journal of Educational Technology, 33(5), 32-49. https:/ / doi.org/10.14742/ ajet. 2884

Taher, D. (2017). The effect of the difference in the source of support in the environment of social networks on the development of learning skills in projects via the web among high school students in computer science [Unpublished Master Thesis]. Ain Shams University.

Thomas, W. \& MacGregor, S. (2005). Online ProjectBased Learning: How Collaborative Strategies and Problem-Solving Processes Impact Performance. Journal of Interactive Learning Research, 16(1), 83-107.

Tolba, A. (2009). The difference in the size of participation groups in project-based e-learning 
and its impact on the acquisition of both instructional design skills, critical thinking, and the attitude towards electronic participation using interactive web technologies among students of the Education Technology Division of the College of Education. Educational Technology Journal, 19(4), 95152.

Woodall, D. (2010). Blended learning strategies: Selecting the best Instructional Method. http://classtap.pb works.com/f/SkillSoft+-+Blended+Elearning.pdf

Yu-Hui, C., \& Yu-Chang, H. (2013). Peer feedback to facilitate project-based learning in an online environment. International Review of Research in Open and Distance Learning, 14(5), 259-276. https:/ / doi.org/10.19173/irrodl.v14i5.1524
Zhang, K., Peng, S. W., \& Hung, J. (2009). Online collaborative learning in a project-based learning environment in Taiwan: a case study on undergraduate students' perspectives. Educational Media International, 46(2), 123-135. https:/ / doi.org/10.1080/09523980902933425

Zheng, X., \& Wang F. (2008). Construction of projectbased virtual learning community. In: F. Li, J. Zhao, T. K. Shih, R. Lau, Q. Li, \& D. McLeod (Eds.), Advances in web based learning - ICWL 2008. ICWL 2008. Lecture Notes in Computer Science, 5145. Springer, Berlin, Heidelberg. https://doi.org/ 10.1007/978-3-540-85033-5_30

\section{http://www.ejmste.com}

